\title{
A Quantitative Pilot Study of Engineering Graduate Student Identity
}

\author{
Mr. Nathan Hyungsok Choe, The University of Texas, Austin
}

Nathan (Hyungsok) Choe is a doctoral student in STEM education at UT Austin. His research focuses on the development of engineering identity in graduate school and underrepresented group. Nathan holds a master's and bachelor's degree in electrical engineering from Illinois Tech. He also worked as an engineer at LG electronics mobile communication company.

\section{Dr. Maura Borrego, University of Texas, Austin}

Maura Borrego is Associate Professor of Mechanical Engineering and Curriculum \& Instruction at the University of Texas at Austin. She previously served as a Program Director at the National Science Foundation, on the board of the American Society for Engineering Education, and as an associate dean and director of interdisciplinary graduate programs. Her research awards include U.S. Presidential Early Career Award for Scientists and Engineers (PECASE), a National Science Foundation CAREER award, and two outstanding publication awards from the American Educational Research Association for her journal articles. Dr. Borrego is Deputy Editor for Journal of Engineering Education. All of Dr. Borrego's degrees are in Materials Science and Engineering. Her M.S. and Ph.D. are from Stanford University, and her B.S. is from University of Wisconsin-Madison.

\section{Dr. Luis L. Martins, University of Texas, Austin}

Luis L. Martins is a Professor and Chair of the Department of Management at the McCombs School of Business at the University of Texas at Austin, where he also holds the Herb Kelleher Chair in Entrepreneurship, the Juanita Dreibelbis Fellowship in Business and a Provost's Teaching Fellowship. He received his Ph.D. in management and organizational behavior from the Leonard N. Stern School of Business at New York University. His research examines the cognitive underpinnings of various individual, group, and organizational phenomena in work organizations, primarily using cognition and identity theories.

\section{Anita D. Patrick, University of Texas, Austin}

Anita Patrick is a STEM Education doctoral student and Graduate Research Assistant in the Department of Mechanical Engineering and College of Liberal Arts at UT Austin's Population Research Center. She received her BS in Bioengineering from Clemson University where she tutored undergraduate mathematics and science courses, and mentored undergraduate engineering majors. Prior to coming to UT, she independently tutored K12 and undergraduate mathematics and science. Her research interests include engineering education, identity and equity. Address: Engineering Training Center II (ETC) 204 East Dean Keeton Street Austin, TX 78712 Email: apatrick@utexas.edu

\section{Dr. Carolyn Conner Seepersad, University of Texas, Austin}

Associate Professor of Mechanical Engineering 


\title{
A Quantitative Pilot Study of Engineering Graduate Student Identity
}

\begin{abstract}
The aim of this research paper is to develop a multi-item survey instrument to assess and understand engineering graduate students' identity. Individuals can develop multiple identities in the academic domain, and we anticipate that graduate students develop both an engineering identity and a research identity in their engineering graduate programs. Engineering identity development has mainly been investigated with undergraduate engineering students. The literature on graduate students' engineering identity development is relatively sparse, and the phenomenon has been investigated mostly using qualitative studies. Furthermore, research identity development has been studied with non-engineering doctoral students, but very few researchers have investigated engineering graduate students' research identity, even though engineering graduate students engage in research and develop research proficiency during their graduate studies. In this quantitative study, we incorporate findings from previous qualitative studies of engineering identity and researcher identity to 1) assess engineering identity and investigate its relationships with key factors affecting engineering identity development and 2) investigate researcher identity development among other graduate programs to investigate relationships between engineering graduate students' research identity and key factors affecting its development.
\end{abstract}

We developed multi-item scales to measure engineering identity and research identity. Several items were borrowed and modified from undergraduate engineering identity studies and research identity studies in different disciplines. In addition, our survey included items that we generated to measure key factors that prior research suggests may affect these identities, namely engineering and research competencies, interest, and recognition. The survey was completed online by 115 mechanical engineering graduate students from a large public research university. Exploratory factor analysis indicated that the items intended to measure engineering and research identities loaded onto their respective factors, and that the items created to measure engineering and research competencies, interest, and recognition loaded onto six factors: Engineering Competence, Engineering Interest, Research Competence, Research Interest, Math/Science Competence, and Interpersonal Skill Competence. Pearson correlation analysis indicated that engineering identity and research identity were significantly correlated with all independent variables except for Interpersonal Skill Competence. In addition, students' intention to complete their program is significantly correlated with Engineering Identity, Engineering Interest, Research Interest, and Math/Science Competence.

\section{Introduction}

In the United States, engineering graduate degrees are increasingly valued by various industries for skills like conducting research and integrating the newest engineering technologies (Brown \& Linden, 2008). However, researchers have reported that the completion rate for U.S. engineering graduate degrees has held steady at just 50\% for the past several decades despite consistent efforts to increase enrollment and retention of engineering graduate students (Bowen \& Rudenstine, 1992; Nerad \& Cerny, 1993). Identity has emerged as a relatively new lens for studying graduate student retention. 
Researchers have reported that the strength of graduate students' identities increased with their competency levels as well as their professional and academic motivation (Alexander, 2011; Silver, Garver, \& Watkins, 2011; Virgil, 2016). When students have greater competence in their disciplinary and research skills, they are more likely to have stronger graduate student identities and higher completion rates for their degrees (Ampaw \& Jaeger, 2012; Burt, 2014). Therefore, understanding graduate students' identity formation is important to understanding their academic achievement, well-being, and retention. However, the literature at the graduate school level on engineering identity and the factors that affect it is relatively limited compared to that on undergraduate students' engineering identity and research identity for other graduate programs. Therefore, additional research on the engineering identity and research identity of engineering graduate students is necessary.

In this research, we define identity as how an individual defines oneself as a "kind of person" (Gee, 2000). Engineering identity can be defined as knowledge, emotions, skills, and experiences that are organized around a particular professional role (Eliot \& Turns, 2011). Thus engineering identity can be unique compared to science and math identity because engineering identity refers to both discipline and profession whereas science and math identity is disciplinary. According to several studies on undergraduate engineering identity(Capobianco, French, \& Diefes-Dux, 2012; Meyers, Ohland, Pawley, Sillman, \& Smith, 2012), engineering students develop their engineering identity during their program. Thus, many engineering graduate students may already have a strong engineering identity due to their undergraduate engineering program experiences, which they choose to expand by matriculating in a graduate program. (The other graduate students who did not obtain undergraduate degrees in engineering may start with lower levels of engineering identity.) However, in all cases, engineering graduate students can develop or strengthen their engineering identities by acquiring engineering and research skills from advisors and research collaborators (Burt, 2014).

According to Burt (2014), engineering graduate students develop their identities through research experiences in their program, and identity development is influenced by several factors including level of competence in engineering and research, and collaborations with other research group members. However, fewer studies on engineering graduate students' identities have been conducted compared to other disciplines, such as social science, medicine, law, and counseling (Auxier, Hughes, \& Kline, 2003; Chen, 2014; Coryell, Wagner, Clark, \& Stuessy, 2013; Hall \& Burns, 2009; Niemi, 1997; Virgil, 2016). These studies inform our understanding of how engineering graduate students develop a distinct identity as a researcher apart from any identity as an engineer (Research identity refers to graduate students defining themselves as a researcher.). Graduate students usually develop their research identities during their graduate program (Colbeck, 2008; Hall \& Burns, 2009). According to Chen (2014), graduate students' research identity can be developed in three ways: performing research, thinking about oneself as a researcher, and being thought of as a researcher. Graduate students' research identities develop as they gain research skills and knowledge in their graduate programs. One result of having a strong research identity is demonstrating specific research skills in the discipline (Svyantek, Kajfez, \& McNair, 2015).

Studies of undergraduate engineering identity have tended to adapt science and math identity studies to focus on the disciplinary aspects of engineering identity. In science, identity -- as 
composed of recognition, performance/competence, and interest factors -- is used as a predictor of choice and persistence in STEM fields (Carlone \& Johnson, 2007; Hazari, Sonnert, Sadler, \& Shanahan, 2010). In engineering, the majority of studies have utilized math and science or physics identity factors to predict identity. Recently, identity factors have been developed to specifically measure engineering identity (Godwin, 2016; Prybutok, Patrick, Borrego, Seepersad, \& Kirisits, 2016 ). The theoretical framework for the current study builds on prior work on science and engineering identity which identifies three main factors related to the identity: performance/competence, interest and recognition. Performance/competence describes a student's belief in their ability to perform academically or when conducting engineering-related tasks, and their ability to understand engineering material. Interest describes how motivated a student is toward the content and career they are pursuing, often encompassing the motives a student has for pursuing graduate study. Interest encompasses not only affinity towards engineering tasks but also the ongoing reasons students identify for persisting in engineering. Recognition describes how others such as parents, relatives, friends, colleagues and faculty see the student in the context of engineering. How that message is transferred to the student often affects their self-recognition i.e., their identifications as engineers.

In the current study, we build on these three factors to derive factors that are specifically related to engineering and research identities of graduate engineering students. We propose that developing survey instruments to measure engineering and research identities of engineering graduate students as well as to measure key factors affecting engineering graduate students' identity formation will eventually contribute to greater understanding of engineering graduate students' intentions to graduate from their program and their academic motivations.

\section{Current study}

To measure the dependent variable of engineering graduate students' engineering identity, we borrowed five items from Plett, Hawkinson, VanAntwerp, Wilson, and Bruxvoort (2011)'s engineering identity scale. Similarly, we expect that the dependent variable of research identity can be measured with a modified version of Plett et al.'s five items. In addition, we propose a model of key factors affecting engineering graduate students' identities as shown in Figure 1. Constructs capturing the key factors affecting engineering identity and research identity are adapted from the undergraduate science and engineering identity model (Carlone \& Johnson, 2007; Godwin, 2016; Hazari et al., 2010; Prybutok et al., 2016 ). Based on the identity model, we expect that graduate students' engineering identities will be affected by three factors: engineering competence/performance, engineering interest, and recognition as an engineer by others. On the other hand, previous work on research identity does not provide a framework for measuring research identity. Therefore, we have adapted the engineering identity model to research identity. We expect that research identity will be affected by three factors: research competence/performance, research interest, and recognition as a researcher by others. Additionally, we include interpersonal skill competence in the framework because interpersonal skill competence affects both engineering and research identity, since these skills included are relevant to both identities. 


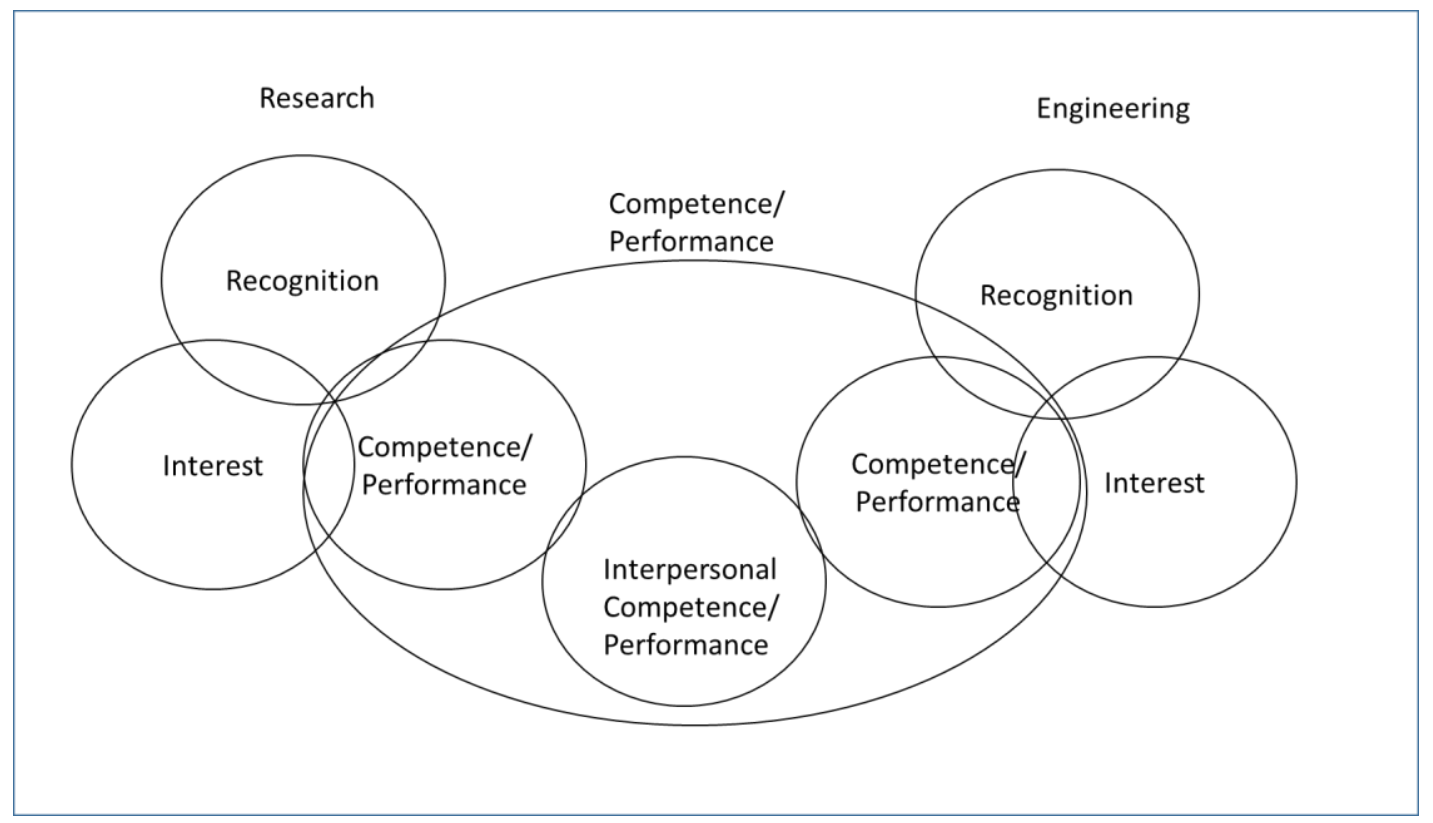

Figure 1. Initial framework of factors affecting engineering graduate student identities.

\section{Methodology}

\section{Survey Development}

For item construction, we generated and modified a total of 81 items to measure engineering graduate student identities as well as the seven factors that we predicted would affect them. We modified and generated items from a literature review, existing survey instruments and pilot interviews. We reviewed several studies on engineering graduate students' academic experiences and their identities. In terms of utilizing existing survey instruments, we borrowed and used five items from engineering identity scales (Plett et al., 2011) and modified these engineering identity items to measure research identity.

We also borrowed items from several constructs to assess engineering graduate student identity including engineering components from undergraduate engineering identity instruments (Patrick et al., 2017; Prybutok et al., 2016 ) and research components from other graduate student instruments (Bieschke, Bishop, \& Garcia, 1996). Because original items were not specifically developed for the target population, we interviewed several key informants to provide context on engineering graduate students' experiences as they related to their engineering and research identities. The key informants were one $\mathrm{PhD}$ engineering faculty member, one $\mathrm{PhD}$ postdoctoral fellow, one PhD engineer in industry, and four $\mathrm{PhD}$ and two master's students. All interviewees were either employed by or alumni of the same large public research university. Some of the interview questions were "do you consider yourself an engineer?" "do you consider yourself a researcher?" and "describe a moment when you felt you were doing well in engineering? What contributed to this success?"

The initial 81 items were also reviewed by a panel of four professors and eight graduate students in engineering and education disciplines and one $\mathrm{PhD}$ engineer to confirm face validity of the 
items. The panel reviewed and assessed clarity of item content and relevance of survey items for each construct of engineering graduate student identity and its predictors. After several iterations, 58 items were retained for the study.

Of the 58 items, 10 measured the two dependent variables: engineering identity and research identity with five items each. The other 48 items measured the seven constructs depicted in Figure 1: engineering competence/performance, recognition as an engineer, engineering interest, research competence/performance, recognition as a researcher, research interest, and interpersonal skill competence/performance. Each construct is measured using at least four survey items. Responses to all dependent and independent variable items were on 5-point Likert scales. The survey stems for the items assessing identity were: "to what extent do you disagree or agree with the following statements;" those assessing competencies were: "how competent are you with the following tasks;" those assessing interest were: "to what extent do you disagree or agree with the following statements;" and those assessing recognition were: "to what extent do you disagree or agree with the following statements?" In addition to the items measuring identities, competencies, interest and recognition, 23 additional questions assessing variables such as demographics, academic background, and career choice were included in the survey.

\section{Data Collection}

The surveys were distributed via an email invitation from the mechanical engineering graduate student coordinator to all current graduate students in mechanical engineering at a large public research university. The graduate students were able to access surveys via the online survey tool, Qualtrics. The graduate coordinator sent one email invitation and two weekly reminders. Participants who completed the survey were entered into a drawing for one of two $\$ 50$ gift cards. A total of 115 students completed the survey resulting in a response rate of $37 \%$. Among respondents, 64 were doctoral students, 35 were thesis master's students, and 16 were non-thesis master's students. Twenty-nine participants self-identified as women, and 86 identified as men. Of 115 students, 63 domestic and 52 international students participated the survey.

\section{Data Analysis}

We conducted an exploratory factor analysis (EFA) using IBM SPSS ${ }^{2} 24$ to investigate the factor structure underlying the new items and eliminate either irrelevant or cross loaded items. Two separate EFA analyses were conducted to analyze the dependent variables and independent variables. It was necessary to use EFA over confirmatory factor analysis (CFA) since the scales used were derived from those developed for undergraduate engineering students or for constructs related to the research identity of graduate students in other fields. In particular, the measures of research interest, research competence/performance and recognition as a researcher, that influence research identity as shown Figure 1 have not been previously tested. Thus, we used EFA to explore the underlying factors captured by the measures in this study (Child, 1990).

For both analyses, we extracted factors using Principal Axis Factoring (PAF), which provides determinations of factor structure to interpret (Loewen \& Gonulal, 2015). PAF was used for this study over maximum likelihood because "PAF generally outperforms (maximum likelihood), except for complex cases of model misspecification and unequal loadings within factors, 
particularly when these factors are correlated. In other words, for a relatively simple factor pattern, or when weak factors are present, PAF is the method of preference" (de Winter \& Dodou, 2012, p. 708). Thus, PAF is a better factoring extraction method for this study because we expected to have a relatively simple factor pattern. We conducted Oblique (non-orthogonal) rotation because based on the theory, we expected that the factors could be inter-correlated with each other (Velicer \& Jackson, 1990). We eliminated all items that had either low loadings onto a factor or significant cross-loadings across factors. Items that had less than a 0.40 factor loading on any factor were eliminated, and crossloaded items with a loading higher than 0.32 on multiple factors were eliminated (Field, 2009). For internal consistency, we calculated Cronbach's alpha values for each retained factor. In addition, we calculated Pearson correlations to find associations among measures of engineering identity and research identity, as well as the factors assessing the independent variables.

Table 1. Exploratory Factor Analysis Results for Survey Measures of Engineering and Research Identities

\begin{tabular}{lll}
\hline \multicolumn{1}{c}{ Factor } & \multicolumn{1}{c}{ Survey Items } & $\begin{array}{l}\text { Factor } \\
\text { Loading }\end{array}$ \\
\hline Engineering & I consider myself an engineer & 0.86 \\
Identity & I am proud to be an engineer & 0.75 \\
$(\alpha=0.83)$ & Being an engineer is an important reflection of who I am & 0.69 \\
& I feel strong ties to other engineers in my discipline & 0.59 \\
\hline Research Identity & I consider myself a researcher & 0.98 \\
$(\alpha=0.89)$ & I am proud to be a researcher & 0.78 \\
& Being a researcher is an important reflection of who I am & 0.77 \\
& I feel strong ties to other researchers in my discipline & 0.69 \\
\hline
\end{tabular}

\section{Results}

\section{Exploratory Factor Analysis}

Dependent variables: The EFA on the 10 items created to measure the dependent variables resulted in a two-factor solution, and each factor has four items after eliminating two items which did not load onto either factor (factor loadings were less than 0.40 for either factor). These items related to how society views engineers. Cronbach's alpha value, an indicator of internal consistency, was 0.83 for engineering identity and 0.89 for research identity, which are both well within the acceptable range (Brace, Kemp, \& Snelgar, 2012) (See Table 1.).

Independent variables: We conducted an EFA on the 48 items created to assess the independent variables. After following EFA guidelines for item-to-factor loadings (Comrey \& Lee, 2013) and content validity, 22 items remained, which loaded onto six factors. The six-factor solution was chosen based on the fact that the scree plot indicated a potential six-factor solution, and that tests of five and seven factors indicated a better fit for the six-factor solution. We identified and labeled the six factors based on the initial theoretical framework and the items that constituted each factor. Whereas most of the items assessing engineering and research competencies and interest loaded as expected, those assessing engineering and research recognition did not. Table 2 shows the label, items, item factor loadings, and Cronbach's alpha 
reliability value for each of the six factors. Each factor consists of three or four items. The Cronbach's alpha values of five of the six factors are well above the 0.70 cut-off which is the minimum standard, and the alpha value for the sixth factor is 0.67 , which is very close to the cutoff. Sixth factor was retained in subsequent analyses due to its consistency with our theoretical framework.

Table 2. Exploratory Factor Analysis Results for Survey Measures of Engineering and Research Competencies and Interest

\begin{tabular}{|c|c|c|}
\hline Factor & Survey Items & $\begin{array}{l}\text { Factor } \\
\text { Loading }\end{array}$ \\
\hline Engineering & Creating prototypes to test an idea & 0.92 \\
\hline \multirow[t]{3}{*}{$\begin{array}{l}\text { Competence } \\
(\alpha=0.84)\end{array}$} & $\begin{array}{l}\text { Designing a system, a part/component of a system, or a } \\
\text { process based on realistic constraints }\end{array}$ & 0.71 \\
\hline & $\begin{array}{l}\text { Building and testing systems to learn more about how they } \\
\text { work }\end{array}$ & 0.61 \\
\hline & Designing and conducting experiments to test a research idea & 0.59 \\
\hline Engineering & In general, I find working on engineering projects interesting & 0.88 \\
\hline Interest & I like doing engineering & 0.84 \\
\hline \multirow[t]{2}{*}{$(\alpha=0.88)$} & I am interested in my engineering work & 0.78 \\
\hline & I am interested in learning more about engineering & 0.68 \\
\hline \multirow{5}{*}{$\begin{array}{l}\text { Research } \\
\text { Competence } \\
(\alpha=0.78)\end{array}$} & Obtaining research articles relevant to my research from & 0.70 \\
\hline & library systems or online & \\
\hline & Keeping up to date on research topic(s) & 0.59 \\
\hline & Replicating key findings in journal papers & 0.56 \\
\hline & Understanding research trends and topic(s) & 0.52 \\
\hline \multirow{3}{*}{$\begin{array}{l}\text { Research Interest } \\
(\alpha=0.83)\end{array}$} & In general, I find working on research interesting & 0.80 \\
\hline & I like doing research & 0.70 \\
\hline & I am interested in my research topic & 0.60 \\
\hline \multirow{3}{*}{$\begin{array}{l}\text { Math/Science } \\
\text { Competence } \\
(\alpha=0.81)\end{array}$} & $\begin{array}{l}\text { Understanding and applying scientific and mathematical } \\
\text { relationships based on the conditions }\end{array}$ & 0.80 \\
\hline & $\begin{array}{l}\text { Applying math and science concepts to make new } \\
\text { systems/models }\end{array}$ & 0.70 \\
\hline & Using calculations and equations to evaluate things & 0.60 \\
\hline Interpersonal Skill & Working with people with different skills and interests & 0.77 \\
\hline \multirow[t]{3}{*}{$\begin{array}{l}\text { Competence } \\
(\alpha=0.67)\end{array}$} & $\begin{array}{l}\text { Communicating verbally, for example in discussion with } \\
\text { others }\end{array}$ & 0.55 \\
\hline & Convincing others to accept my ideas & 0.49 \\
\hline & Learning new things from people I'm working with & 0.45 \\
\hline
\end{tabular}

Compared to the initial seven constructs, the EFA extracted the six factors depicted in Figure 2.

Engineering Competence. This factor is composed of four items and represents engineering graduate students' perception of mastering challenging engineering knowledge and skills. All items were from the initial framework of the engineering competence/performance construct. 
Engineering Interest. Four items were associated with engineering graduate students' interest in learning and working in engineering. All four items were from the same construct that we intended to be part of engineering interest.

Research Competence. This factor is also composed of four items that indicate graduate students' perception of mastering challenging research knowledge and skills. All four items extracted were from the same research competence/performance initial construct.

Research Interest. This factor was made up of three items which represent research interest of engineering graduate students, i.e., their interest in working on and learning about research. All three items were from the initial framework of the research interest construct.

Math/Science Competence. This factor captures engineering graduate students' perception of mastering mathematics and science in their graduate program, which can be considered fundamental knowledge/skills for engineering graduate students. Math/science competence as a construct was not a part of the initial framework. This factor was made up of two items initially designed to assess the research competence/performance construct, and one that was designed to assess the engineering competence/performance construct. This new factor represents the fact that graduate students may consider math and science knowledge/skill as an important aspect of competence that is separate from engineering competence and research competence.

Interpersonal skills Competence. This factor includes four items assessing interpersonal skills competence, and assesses graduate students' perception of mastering psychological competencies needed for proper interaction with others for academic success. All items included in this factor were among those intended to assess interpersonal skills competence in our initial set of items.

The items intended to assess two of the constructs in our initial framework, recognition as an engineer by the engineering profession and recognition as a researcher by the engineering profession, did not load as expected in the EFA, and were not retained for further analyses.

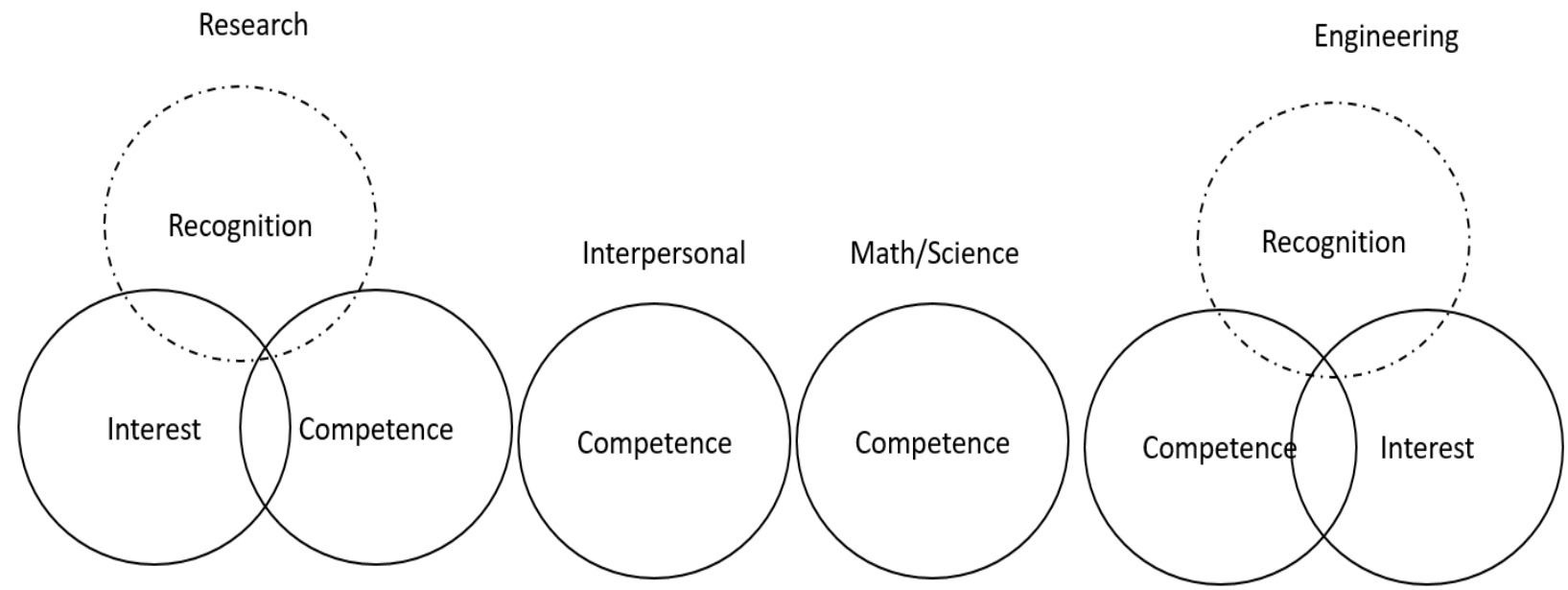

Figure 2. Engineering Graduate Student Identity Model 
Note: Dashed circle indicates that the initial construct is no longer a factor in the model.

\section{Pearson Correlation}

We calculated Pearson correlations to investigate correlations among the dependent variables of engineering identity, research identity and intention to complete their degree, and the independent variables assessing factors expected to affect graduate student identity. The results of the correlation analysis are presented in Table 3 . The correlation between engineering identity and research identity is positive and significant $(\mathrm{r}=.49, \mathrm{p}<.01)$, which indicates that these two identities may be mutually reinforcing among graduate engineering students. In addition, engineering identity is positively and significantly correlated with all factors except interpersonal skills competence. As we expected, engineering competence and engineering interest factors are positively correlated with engineering identity. However, it is interesting that research competence and research interest are also positively correlated with engineering identity. Further, research identity is also positively correlated with all factors except interpersonal skills competence. Similar to the case of engineering identity, research identity is not only related to research competence and interest as we expected, but also to engineering competence and interest. Math/science competence is also positively correlated with both engineering identity and research identity. Taken together, the fact that all engineering and research interest and competence variables as well as the math/science competence variable were positively related to both engineering and research identity, indicates that both identities are likely affected by the same underlying drivers, and buttresses the idea that the two identities are mutually reinforcing.

In addition, we conducted Pearson correlations between students' intention to complete their degree and their identities and factors that influence their identities. Intention to complete is correlated with engineering identity but not research identity. However, intention is also correlated with engineering interest, research interest, and math/science competence. This preliminary results suggests that future work with a larger sample and refined scales may reveal important relationships between intention to complete a graduate degree, engineering identity and research and engineering interest. 
Table 3. Correlations among identity variables and the six factors assessing engineering and research competencies and interest $(\mathrm{N}=115)$

\begin{tabular}{|c|c|c|c|c|c|c|c|c|c|}
\hline & $\begin{array}{l}\text { Mean } \\
\text { (SD) }\end{array}$ & 1 & 2 & 3 & 4 & 5 & 6 & 7 & 8 \\
\hline $\begin{array}{l}\text { 1. Engineering } \\
\text { Identity }\end{array}$ & $\begin{array}{c}4.11 \\
(0.73)\end{array}$ & 1 & & & & & & & \\
\hline $\begin{array}{l}\text { 2. Research } \\
\text { Identity }\end{array}$ & $\begin{array}{c}3.78 \\
(0.92)\end{array}$ & $0.49 * *$ & 1 & & & & & & \\
\hline $\begin{array}{l}\text { 3. Research } \\
\text { Competence }\end{array}$ & $\begin{array}{c}3.55 \\
(0.72)\end{array}$ & $0.30 * *$ & $0.49 * *$ & 1 & & & & & \\
\hline $\begin{array}{l}\text { 4. Research } \\
\text { Interest }\end{array}$ & $\begin{array}{c}3.91 \\
(0.89)\end{array}$ & $0.42 * *$ & $0.81 * *$ & $0.51 * *$ & 1 & & & & \\
\hline $\begin{array}{l}\text { 5. Engineering } \\
\text { Competence }\end{array}$ & $\begin{array}{c}3.63 \\
(0.79)\end{array}$ & $0.35^{* *}$ & $0.35^{* *}$ & $0.34 * *$ & $0.29 * *$ & 1 & & & \\
\hline $\begin{array}{l}\text { 6. Engineering } \\
\text { Interest }\end{array}$ & $\begin{array}{c}4.26 \\
(0.61)\end{array}$ & $0.63 * *$ & $0.28 * *$ & $0.19 *$ & $039 * *$ & $0.21 *$ & 1 & & \\
\hline $\begin{array}{l}\text { 7. Math/Science } \\
\text { Competence }\end{array}$ & $\begin{array}{c}3.95 \\
(0.75)\end{array}$ & $0.25 * *$ & $0.35^{* *}$ & $0.49 * *$ & $0.29 * *$ & $0.39 * *$ & 0.12 & 1 & \\
\hline $\begin{array}{l}\text { 8. Interpersonal } \\
\text { Skill } \\
\text { Competence }\end{array}$ & $\begin{array}{c}4.01 \\
(0.55)\end{array}$ & 0.14 & 0.04 & $0.20 *$ & 0.11 & $0.22 *$ & $0.27 * *$ & $0.25 * *$ & 1 \\
\hline $\begin{array}{l}\text { 9. Intend to } \\
\text { complete } \\
\text { degree }\end{array}$ & $\begin{array}{c}4.79 \\
(0.43)\end{array}$ & $0.23 *$ & 0.13 & 0.16 & $0.30 * *$ & 0.14 & $0.21 *$ & $0.27 * *$ & 0.16 \\
\hline
\end{tabular}

\section{Discussion}

This pilot study attempted to develop a theoretical model of engineering identity development of engineering graduate students. The results of the exploratory factor analysis generally aligned with the initial framework that we developed from studies on undergraduate engineering identity and graduate identity in other fields. Specifically, the results suggest that engineering graduate students have separate but mutually reinforcing engineering and research identities. Separate interest and competence factors for engineering and research, as well as a separate factor for professional skills competence, emerged as expected. Other competence items factored separately into math/science competence. Of particular note, although items for research and engineering recognition were included, no factors related to recognition emerged from the EFA. This is in contrast with undergraduate engineering identity studies (Godwin, 2016; Prybutok et al., 2016 ) for which recognition emerges or persists in factor analyses. Recognition items included "my advisor sees me as an engineer," and "my peers view me as an engineer." One possible reason for this finding is that graduate students may not view the opinions of faculty and peers as related. Another potential reason is that they do not need to rely as much on their perceptions of the opinions of others. Unlike undergraduates, graduate students may have other accomplishments or validations that serve as recognition, including engineering bachelor's or 
master's degrees, full-time work experience, or licenses. Recognition items may need to be modified and added in order to consider graduate students' unique acknowledgements such as obtaining a bachelor's degree in engineering or being a co-author on a published peer-reviewed paper as accomplishments relevant to engineering or research recognition.

The results also showed some promising relationships between the identity factors. As shown in Table 3, engineering graduate students have strong engineering (mean $=4.11$ on 5 -point Likert scale) and research (mean=3.78) identities which are positively and significantly correlated to each other. Further, engineering identity, engineering interest, research interest, and math/science competence were all correlated with participants' intention to complete their graduate degrees.

At this early stage, it is difficult to suggest practical implications of the findings. Engineering and research interest are the most highly correlated to engineering and research identity and intention to complete the graduate degree (Table 3). These interest scales are composed mostly of simple items such as "I like doing research," but also items about interesting "engineering work" and "research topic" (Table 2). Clearly, graduate students should be engaged in coursework, projects and research that interests them. The mean of engineering interest is particularly high (4.27, Table 3), which is to be expected among a group that has completed undergraduate degrees and made the decision to pursue additional engineering education. The key to intervention may be math/science competence, which focuses on the ability to apply math and science to problems using relationships, models and analysis. Respondents' confidence in these skills was both higher than in engineering and research skills (competence) and more highly correlated with intention to complete than any other factor, including identity.

\section{Limitations}

There are several limitations in this study. The data is collected from one department at a single institution, so this study cannot generalize to the broader engineering graduate student population. Collecting more data by surveying other departments at the same institution or at several other institutions would help to generalize results about engineering graduate student identity. In addition, a larger sample size would improve scale validation by supporting a confirmatory factor analysis.

\section{Conclusion and Future Work}

This study describes a pilot instrument development, but the results are promising because they align with the prior theory on which the study is based. Exploratory factor analysis identified six factors: engineering competence, engineering interest, research competence, research interest, math/science competence, and interpersonal skill competence. In future development of the survey instruments, we will add additional items to improve the reliability of some of the scales. Additional future analyses will include $t$-tests or ANOVA by different groups to find differences in engineering identity and research identity across demographic and other characteristics. For example, it will be interesting to examine differences in results across groups that are different in gender, race, nationality, year of program, and undergraduate degree (engineering vs. nonengineering). In addition, we will also run regression models to explore how independent

variables/factors predict engineering graduate students' engineering identity and research 
identity, as well as the roles played by gender, race, and nationality in influencing graduate students' identities.

\section{Acknowledgements}

This research was funded by the National Science Foundation through grants \#1636449 and \#1636404). We thank the other members of our team, Dr. Catherine Riegle-Crumb and Dr. Meagan Kendall, as well as the many faculty members and students that made the collection of this data possible. Any opinions, findings, and conclusions in this article are the authors' and do not necessarily reflect the views of the National Science Foundation.

\section{References}

Alexander, C. (2011). Learning to be lawyers: Professional identity and the law school curriculum. Maryland Law Review, 70(2), 465-483.

Ampaw, F. D., \& Jaeger, A. J. (2012). Completing the three stages of doctoral education: An event history analysis. Research in Higher Education, 53(6), 640-660.

Auxier, C., Hughes, F. R., \& Kline, W. B. (2003). Identity development in counselors-intraining. Counselor Education and Supervision, 43(1), 25-39.

Bieschke, K. J., Bishop, R. M., \& Garcia, V. L. (1996). The utility of the research self-efficacy scale. Journal of Career Assessment, 4(1), 59-75.

Bowen, W. G., \& Rudenstine, N. L. (1992). In pursuit of the Ph. D. Princeton, NJ: Princeton University Press.

Brace, N., Kemp, R., \& Snelgar, R. (2012). SPSS for Psychologists (Vol. 5th edition). New York, NY: Routledge.

Brown, C., \& Linden, G. (2008). Is there a shortage of engineering talent in the US? Institute for Research on Labor and Employment.

Burt, B. A. (2014). The influence of doctoral research experiences on the pursuit of the engineering professoriate. (Doctoral Dissertation), University of Maryland-College Park.

Capobianco, B. M., French, B. F., \& Diefes-Dux, H. A. (2012). Engineering identity development among pre-adolescent learners. Journal of Engineering Education, 101(4), 698.

Carlone, H. B., \& Johnson, A. (2007). Understanding the science experiences of successful women of color: Science identity as an analytic lens. Journal of Research in Science Teaching, 44(8), 1187-1218.

Chen, S. (2014). Balancing knowing and not-knowing: an exploration of doctoral candidates' performance of researcher selves in the dissertation defence. Assessment \& Evaluation in Higher Education, 39(3), 364-379.

Child, D. (1990). The essentials of factor analysis. New York, NY: Continuum International Publishing Group.

Colbeck, C. L. (2008). Professional identity development theory and doctoral education. New directions for teaching and learning, 113, 9-16. doi:10.1002/t1.304

Comrey, A. L., \& Lee, H. B. (2013). A first course in factor analysis. New York, NY: Psychology Press.

Coryell, J. E., Wagner, S., Clark, M. C., \& Stuessy, C. (2013). Becoming real: Adult student impressions of developing an educational researcher identity. Journal of Further and Higher Education, 37(3), 367-383. 
de Winter, J. C., \& Dodou, D. (2012). Factor recovery by principal axis factoring and maximum likelihood factor analysis as a function of factor pattern and sample size. Journal of Applied Statistics, 39(4), 695-710.

Eliot, M., \& Turns, J. (2011). Constructing professional portfolios: Sense-making and professional identity development for engineering undergraduates. Journal of Engineering Education, 100(4), 630-654.

Field, A. (2009). Discovering statistics using SPSS: Sage publications.

Gee, J. P. (2000). Identity as an Analytic Lens for Research in Education. Review of research in education, 25, 99-125. doi:10.2307/1167322

Godwin, A. (2016). The Development of a Measure of Engineering Identity. Paper presented at the ASEE 2016: American Society for Engineering Education Annual Conference \& Exposition.

Hall, L., \& Burns, L. (2009). Identity development and mentoring in doctoral education. Harvard educational review, 79(1), 49-70.

Hazari, Z., Sonnert, G., Sadler, P. M., \& Shanahan, M. C. (2010). Connecting high school physics experiences, outcome expectations, physics identity, and physics career choice: A gender study. Journal of Research in Science Teaching, 47(8), 978-1003.

Loewen, S., \& Gonulal, T. (2015). Exploratory factor analysis and principal components analysis. In L. Plonsky (Ed.), Advancing Quantitative Methods in Second Language Research (pp. 182-212). New York, NY: Routledge.

Meyers, K. L., Ohland, M. W., Pawley, A. L., Sillman, S. E., \& Smith, K. A. (2012). Factors relating to engineering identity. Global Journal of Engineering Education, 14(1), 119131.

Nerad, M., \& Cerny, J. (1993). From facts to action: Expanding the graduate division's educational role. New directions for institutional research, 1993(80), 27-39. doi:10.1002/ir.37019938005

Niemi, P. (1997). Medical students' professional identity: self-reflection during the preclinical years. Medical education, 31(6), 408-415.

Patrick, A., Choe, H. N., Martins, L., Borrego, M., Kendall, M., \& Seepersad, C. C. (2017). A Measure of Affect towards Key Elements of Engineering Professional Practice. Paper presented at the American Society for Engineering Education Annual Conference, Columbus, $\mathrm{OH}$.

Plett, M., Hawkinson, C., VanAntwerp, J. J., Wilson, D., \& Bruxvoort, C. (2011). Engineering identity and the workplace persistence of women with engineering degrees. Paper presented at the American Society for Engineering Education Annual Conference \& Exposition, Vancouver, Canada.

Prybutok, A., Patrick, A. D., Borrego, M. J., Seepersad, C. C., \& Kirisits, M. J. (2016 ). Crosssectional Survey Study of Undergraduate Engineering Identity. Paper presented at the ASEE Annual Conference \& Exposition, New Orleans, Louisiana.

Silver, C., Garver, A., \& Watkins, L. (2011). Unpacking the apprenticeship of professional identity and purpose: insights from the Law School survey of student engagement. Journal of the Legal Writing Institute, 17, 373-408.

Svyantek, M. V., Kajfez, R. L., \& McNair, L. D. (2015). Teaching vs. Research: An Approach to Understanding Graduate Students' Roles through ePortfolio Reflection. International Journal of ePortfolio, 5(2), 135-154. 
Velicer, W. F., \& Jackson, D. N. (1990). Component analysis versus common factor analysis: Some issues in selecting an appropriate procedure. Multivariate behavioral research, 25(1), 1-28.

Virgil, S. M. (2016). The Role of Experiential Learning on a Law Student's Sense of Professional Identity. Wake Forest Law Review, 51, 325-338. 